\title{
Pyrroloquinoline based Styryl Dyes Doped PMMA, PS, and PS/TiO2 Polymer for Fluorescent Applications
}

GANAPATI SHANKARLING ( $\sim$ gsshankarling@gmail.com )

Institute of Chemical Technology

Mahesh Jachak

Institute of Chemical Technology

Rupali Bhise

Institute of Chemical Technology

Ankur Chaturvedi

Institute of Chemical Technology

Vidula Kamble

Institute of Chemical Technology

\section{Research Article}

Keywords: Fluorescent styryl dyes, Poly (methyl methacrylate), Fluorescence molecular rotors (FMRs), Polystyrene, Ionic liquid

Posted Date: December 6th, 2021

DOI: https://doi.org/10.21203/rs.3.rs-1124005/v1

License: (9) (i) This work is licensed under a Creative Commons Attribution 4.0 International License.

Read Full License 


\section{Abstract}

This article presents two highly fluorescent donor- $\pi$-acceptor (D- $\pi-A)$ moiety containing an electrondonating carbazole and phenothiazine donors fused with electron-withdrawing pyrrolo-quinoline acceptor dyes, PQC and PQPT. We also discussed the polymerization and film-forming process of dye PQC and PQPT doped in poly (methyl methacrylate) (PMMA) and polystyrene (PS) polymer to find their optical applications in polymer-based technology. We investigated the fluorescent properties of dyes PQC and PQPT from 0.01 - $1 \mathrm{wt}$. \% in poly(methyl methacrylate) (PMMA). We also investigated the changes in the spectrum shape and shift in wavelength with changes in poly(methyl methacrylate) (PMMA), polystyrene (PS), and $\mathrm{TiO}_{2}$ doped in polystyrene $\left(\mathrm{PS} / \mathrm{TiO}_{2}\right)$. The analysis of surface morphology of prepared polymer samples was done with the help of a scanning electron microscope. The thermal and photostability of synthesized dyes in poly (methyl methacrylate) (PMMA), polystyrene (PS), and $\mathrm{TiO}_{2}$ doped in polystyrene (PS/ $\mathrm{TiO}_{2}$ ) were investigated to get detailed information owing to the application of fluorescent polymers in the field of optoelectronic, nanohybrid coatings in solar concentrators, etc.

\section{Introduction}

The poly (methyl methacrylate) (PMMA) is one of the most transparent and durable materials; hence it has been used in many fields and applications such as lenses for glasses [1], LCD screens [2], medical technologies, and implants [3], solid-state dye lasers [4], signs and artistic uses [5].

Polystyrene is cheap, transparent, rigid, easy to mould, and has good electrical properties, which open up the application in different fields such as protective packaging [6], automobile parts [7], insulation, and electronics [8], etc.

The addition of small amounts of fluorescent dye in the polymer can make the polymer fluorescent. A fluorescent dye-doped in epoxy polymer used to identify cracks and self-healing coating $[9,10,11]$, transparent biocompatible [12], grafted to glass [13], repair of artifacts [14, 15], solar concentrators [16], and holographic patterning [17]. Also, the dye-doped in PMMA and polystyrene (PS) can be used in graded-index polymer optical fiber [18, 19], sensor application $[20,21]$, solvatochromic dye for humidity measurement [22], solar collector [23, 24], and optical bistability [25].

One of the broadly applicable donor-acceptor type dyes are the styryl dyes which possess improved $\pi$ conjugated structures with an increase in intramolecular charge-transfer (ICT) mechanism. The styryl derivatives show high molar absorptivity, good charge transfer characteristics, improved thermal and photostability [26 - 28].

By tuning donor, acceptor, and $\pi$-conjugation system of a dye, resulted in alter the UV to near-infrared spectra for application in various fields such as optical writing and reading [29], red emitter [30], photonic optical fibre [31], optoelectronic telecommunication [32], electroluminescent materials [33], and photovoltaic [34]. 
The high photoluminescence and hole-transport properties are enhanced by electron-rich nitrogen and sulfur atoms in carbazole, quinoline, and thiophene derivatives [35]. Also, carbazole, phenothiazine, and pyrroloquinoline heterocyclic aromatic nature make it chemically and thermally stable, creating prominent optical materials [36].

The main aim of this research is to evaluate the effect on fluorescence in poly (methyl methacrylate) (PMMA) and polystyrene (PS) polymers using new pyrroloquinoline as a common acceptor and carbazole or phenothiazine as a donor of two novel dyes (Fig. 1).

Here, we synthesis of PQC and PQPT dye in a greener way. The UV-vis and fluorescence analysis to determine the modifications in photophysical spectra. We studied the surface morphology and physical strength of polymer samples with the help of a scanning electron microscope and a flexural test. The photostability of the dye-doped polymer was examined by continuous exposer of radiations. The differential scanning calorimetry (DSC) with thermogravimetry (TGA) is widely studied to explore the thermal properties of the polymers.

\section{Experimental Section}

\subsection{Materials and Instruments}

The chemicals and solvents were from Spectrochem Pvt. Ltd., Oxford Lab Fine Chem LLP., and SigmaAldrich Ltd. The poly (methyl methacrylate) (PMMA) and polystyrene (PS) polymer was bought from Sigma-Aldrich and used without further purification. Both dyes absorption and fluorescence properties of their respective polymer samples were studied on a Jasco V-750 Uv-vis spectrophotometer and a Jasco FP-8200 spectrofluorometer, respectively. We recorded the differential scanning calorimetric (DSC) and thermogravimetric (TGA) study of dyes and their polymer matrix on a Jasco instrument. The film thickness was measured by the Fizeau interferometer. The tensile strength, and flexural test of polymeric samples, were carried by Instron ${ }^{\circledR}$ modal no. 5566 . The study of surface morphology of polymeric samples by using a scanning electron microscope (SEM).

\subsection{Experimental Methods}

The primary photophysical study of samples was done by using quartz cuvettes of $1 \mathrm{~cm}$ path length. The slit width of $5 \mathrm{~nm}$ was used to determine the absorbance as well as emission spectra. The experimental conditions were maintained constant in all the experiments. The stock solution of dyes was prepared in chloroform. The dye samples were excited at their higher absorbance wavelength $\left(\lambda_{\max }\right)$. The primary photophysical properties of dyes in solution state were carried out in three different solvents with an increase in polarities at a concentration of $\sim 5 \times 10^{-6} \mathrm{~mol} / \mathrm{L}$. The primary photophysical properties of dyes in poly (methyl methacrylate) (PMMA) was carried at different concentration, and the concentration of maximum fluorescence intensity was further used for polystyrene (PS) samples.

\subsection{Greener synthesis procedure of styryl dyes}


In a round bottom flask, added $2 \mathrm{ml}$ of dichloroethane, 2,3,3,8-Tetramethyl-3H-pyrrolo[3,2-h]quinoline (1) (1 g, 0.0045 mole) and N-butyl carbazole-4-carbaldehyde (2) (1.130 g, 0.0045 mole). Then tetra butyl ammonium bromide (TBAB) $(0.160 \mathrm{~g}, 0.0005$ moles $)$ and $5 \mathrm{ml}$ of choline hydroxide were added and heated at $50^{\circ} \mathrm{C}$ for 3 hours. The completion of the reactionwas checked on silica gel TLC with mobile phase ( $n$-hexane: ethyl acetate (1:1)). Once the reaction was completed, the removal of dichloroethane was carried on a rotavap and filtered to get solidify the product. The obtained crude product was purified by column chromatography using mobile phase ( $n$-hexane: ethyl acetate, (3:2)) to get a yellow-colored solid. Product yield: $(1.130 \mathrm{~g}, 55 \%)$, Melting point: $220^{\circ} \mathrm{C},{ }^{1} \mathrm{H} N M R\left(500 \mathrm{MHz}, \mathrm{CDCl}_{3}, \mathrm{TMS}\right) \delta 8.35(\mathrm{~s}, 1 \mathrm{H})$, $8.16(\mathrm{~d}, J=7.7 \mathrm{~Hz}, 1 \mathrm{H}), 8.11(\mathrm{~d}, J=15.0 \mathrm{~Hz}, 1 \mathrm{H}), 8.08(\mathrm{~s}, 1 \mathrm{H}), 7.81(\mathrm{~d}, J=8.5 \mathrm{~Hz}, 1 \mathrm{H}), 7.67(\mathrm{~d}, J=8.0 \mathrm{~Hz}$, $1 \mathrm{H}), 7.50(\mathrm{~d}, J=7.8 \mathrm{~Hz}, 2 \mathrm{H}), 7.43(\mathrm{dd}, J=8.2,3.9 \mathrm{~Hz}, 2 \mathrm{H}), 7.36(\mathrm{~d}, J=15.0 \mathrm{~Hz}, 1 \mathrm{H}), 7.32(\mathrm{~d}, J=8.4 \mathrm{~Hz}, 1 \mathrm{H})$, $7.28(\mathrm{t}, 1 \mathrm{H}), 4.33(\mathrm{t}, J=7.0 \mathrm{~Hz}, 2 \mathrm{H}), 2.88(\mathrm{~s}, 3 \mathrm{H}), 1.87(\mathrm{~m}, J=15.1,7.0 \mathrm{~Hz}, 2 \mathrm{H}), 1.60(\mathrm{~s}, 6 \mathrm{H}), 1.42(\mathrm{~m}, J=$ $15.1,7.0 \mathrm{~Hz}, 2 \mathrm{H}), 0.96(\mathrm{t}, J=7.0 \mathrm{~Hz}, 3 \mathrm{H})$.

${ }^{13} \mathrm{C} \mathrm{NMR}\left(126 \mathrm{MHz}, \mathrm{CDCl}_{3}\right) \delta 184.5,159.9,147.2,141.4,141.1,140.0,136.4,127.6,127.0,126.2,125.4$, $125.3,123.5,123.0,122.0,120.7,120.4,119.5,119.1,117.8,109.3,109.2,77.2,53.9,43.2,31.3,25.9,24.0$, 20.7, 14.0, ESI-MS: $\mathrm{m} / \mathrm{z}$ calcd for $\mathrm{C}_{32} \mathrm{H}_{31} \mathrm{~N}_{3}\left(\mathrm{M}^{+}\right)$: 458.2596, found: 458.2591. [37]

\subsection{2.(E)-10-butyl-3-(2-(3,3,8-trimethyl-3H-pyrrolo[3,2-h]quinolin-2-yl)vinyl)-10H-phenothiazine (PQPT)}

In a round bottom flask, added $2 \mathrm{ml}$ of dichloroethane, 2,3,3,8-Tetramethyl-3H-pyrrolo[3,2-h]quinoline (1) ( $0.750 \mathrm{gm}, 0.00334 \mathrm{~mole}$ ) and $\mathrm{N}$-butyl phenothiazine 4-carbaldehyde (3) ( $0.947 \mathrm{gm}, 0.00334 \mathrm{~mole})$. Then tetra butyl ammonium bromide (TBAB) $(0.160 \mathrm{~g}, 0.0005$ mole) and $5 \mathrm{ml}$ of choline hydroxide were added and heated at $40^{\circ} \mathrm{C}$ for 6 hours. The completion of the reaction was checked on silica gel TLC with mobile phase ( $n$-hexane: ethyl acetate (1:1)). Once the reaction was completed, the removal of dichloroethane was carried on a rotavap and filtered to get solidify the product. The obtained crude product was purified by column chromatography using mobile phase ( $n$-hexane: ethyl acetate, (3:2)) to get an orange-colored solid. Product yield: $(0.979 \mathrm{~g}, 60 \%)$, Melting point: $180^{\circ} \mathrm{C},{ }^{1} \mathrm{H} \mathrm{NMR}\left(500 \mathrm{MHz}, \mathrm{CDCl}_{3}, \mathrm{TMS}\right) \delta 8.08(\mathrm{~d}, J=$ $8.4 \mathrm{~Hz}, 1 \mathrm{H}), 7.81(\mathrm{~d}, J=15.0 \mathrm{~Hz}, 1 \mathrm{H}), 7.67(\mathrm{~d}, J=8.0 \mathrm{~Hz}, 1 \mathrm{H}), 7.47(\mathrm{~d}, J=8.0 \mathrm{~Hz}, 1 \mathrm{H}), 7.41(\mathrm{~d}, J=8.4 \mathrm{~Hz}$, $1 \mathrm{H}), 7.39(\mathrm{~d}, J=1.5 \mathrm{~Hz}, 1 \mathrm{H}), 7.31(\mathrm{~d}, J=8.4 \mathrm{~Hz}, 1 \mathrm{H}), 7.17-7.13(\mathrm{~m}, 2 \mathrm{H}), 7.10(\mathrm{~d}, J=15.0 \mathrm{~Hz}, 1 \mathrm{H}), 6.92(\mathrm{t}$, $J=7.5 \mathrm{~Hz}, 1 \mathrm{H}), 6.87(\mathrm{~d}, J=4.2 \mathrm{~Hz}, 1 \mathrm{H}), 6.86(\mathrm{~d}, J=4.5 \mathrm{~Hz}, 1 \mathrm{H}), 3.88(\mathrm{t}, J=7.5 \mathrm{~Hz}, 2 \mathrm{H}), 2.87(\mathrm{~s}, 3 \mathrm{H}), 1.81$ $(\mathrm{m}, J=15.0,7.5 \mathrm{~Hz}, 2 \mathrm{H}), 1.52(\mathrm{~s}, 6 \mathrm{H}), 1.47(\mathrm{~m}, J=15.0,7.5 \mathrm{~Hz}, 2 \mathrm{H}), 0.96(\mathrm{t}, J=7.5 \mathrm{~Hz}, 3 \mathrm{H})$.

${ }^{13} \mathrm{C} \mathrm{NMR}\left(126 \mathrm{MHz}, \mathrm{CDCl}_{3}\right) \delta 184.1,159.9,149.1,147.2,146.3,144.6,141.0,137.6,136.5,130.8,127.6$, $127.5,127.4,127.0,126.1,125.5,125.2,124.2,122.8,122.0,119.1,118.1,115.6,115.5,77.2,53.9,47.5$, 29.1, 25.8, 23.6, 20.3, 13.9, ESI-MS: $\mathrm{m} / \mathrm{z}$ calcd for $\mathrm{C}_{32} \mathrm{H}_{31} \mathrm{~N}_{3} \mathrm{~S}(\mathrm{M}+)$ : 490.2317, found: 490.2310.[37]

\section{Results And Discussion}

\subsection{Design and Synthesis}


The synthesized styryl dyes PQC and PQPT containing the same pyrrolo-quinaldine as an acceptor with altered donor units (carbazole for PQC and phenothiazine for PQPT). The N-butyl aliphatic chain was strategically implemented to reduce the recombination or association of dyes [38]. Here, we synthesis these dyes in an environmentally benign process by using an ionic liquid. The detailed synthesis procedure of intermediates is discussed briefly earlier in the previous paper [37].

Choline hydroxide was prepared by adding choline chloride $(2.8 \mathrm{~g}, 0.01 \mathrm{~mole})$ and potassium hydroxide $(1.12 \mathrm{~g}, 0.01 \mathrm{~mole})$ in $30 \mathrm{ml}$ of methanol and then heated at $60^{\circ} \mathrm{C}$ for 12 hours. Afterwards, the methanol was removed from rotavap and further used for synthesis without purification. [39]

The PQC and PQPT were synthesized by using Knoevenagel condensation of 2,3,3,8-tetramethyl-3Hpyrrolo[3,2-h]quinoline (1) with N-butyl carbazole-4-carbaldehyde (2) or N-butyl phenothiazine 4carbaldehyde (3) in dichloroethane with the presence of choline hydroxide and tetra butyl ammonium bromide (TBAB), respectively (Refer scheme 1 ).

\subsection{Preparation of fluorescent PMMA films, PS and PS/TiO ${ }_{2}$ sheets}

\subsubsection{Preparation of fluorescent PMMA films}

We added the PMMA grains with PQC or PQPT fluorescent dyes in dichloromethane $\left(\mathrm{CH}_{2} \mathrm{Cl}_{2}\right)$ solvent and sonicated for $1 \mathrm{~h}$ at $40^{\circ} \mathrm{C}$. The polymer blend was doped with increased PQC or PQPT fluorescent dye concentrations from 0.01 to $1 \mathrm{wt}$. \%. Further on a clean glass petri dish, the polymer blend was cast and kept dry at room temperature. The fluorescent PMMA films were then aged for $4 \mathrm{~h}$ at $55^{\circ} \mathrm{C}$ to remove the remaining solvent. The obtained fluorescent films were cut into $4 \mathrm{~cm}^{2}$ square portions having $100 \pm 10$ $\mu \mathrm{m}$ thickness [40]. Fig. 2 displays a picture of the PQC and PQPT dyes fluorescent PMMA films, which shows that the uniformity of dye in the thin film with an increase in the concentration having yellow and orange shades.

\subsubsection{Preparation of fluorescent PS sheet}

The Polystyrene (PS) sheets were prepared using a melt blending process in a Rheomix 3000 blender machine having a volume capacity of $300 \mathrm{~cm}^{3}$, and counter-rotating roller blades were delivered to the kneader having a residence time of $10 \mathrm{~min}$ at a mixing speed of $100 \mathrm{rpm}$. The $0.3 \mathrm{wt}$ \% of the synthesized dye PQC or PQPT and $200 \mathrm{~g}$ of Polystyrene (PS) were mixed at $220^{\circ} \mathrm{C}$ for $10 \mathrm{~min}$. In an electric-heat curing press, the moulded samples were preheated for 4 minutes, having a temperature of $195-200{ }^{\circ} \mathrm{C}$, and then heat pressed. Subsequently, the piece was then conveyed to a cold-pressing instantly and kept for 10 minutes at $30^{\circ} \mathrm{C}[41,42]$. The coloured PS samples were moulded into $60^{\prime} 40 \mathrm{~mm}$ diameter samples thickness of $1 \mathrm{~mm}, 2 \mathrm{~mm}$, and $3 \mathrm{~mm}$.

\subsubsection{Preparation of $\mathrm{PS} / \mathrm{TiO}_{2}$ nanohybrid sheet}

The preparation of $\mathrm{PS} / \mathrm{TiO}_{2}$ nanohybrid sheet materials by the same instrument which was used in the fluorescent PS sheet preparation. The $0.3 \mathrm{wt}$ \% of the synthesized dye PQC or PQPT, $0.25 \mathrm{wt}$ \% of $\mathrm{TiO}_{2}$ 
powder and $200 \mathrm{~g}$ of Polystyrene (PS) were mixed at $220^{\circ} \mathrm{C}$ for 10 minutes. The moulded sample was heated for $4 \mathrm{~min}$ a having temperature of $195-200^{\circ} \mathrm{C}$ and then heat pressed. Subsequently, the piece was conveyed to a cold-pressing instantly and kept for 10 minutes at $30^{\circ} \mathrm{C}[41,42]$. The coloured PS samples were moulded into $60^{\prime} 40 \mathrm{~mm}$ diameter samples having a thickness of $1 \mathrm{~mm}, 2 \mathrm{~mm}$, and $3 \mathrm{~mm}$.

\subsection{Photophysical properties}

The PQC and PQPT contain the same acceptor but different donor moiety, which results in a change of absorption and emission spectra in the various solvent with an increase in solvent polarity. The difference in photophysical properties causes a shift in the HOMO/LUMO energy bandgap. Therefore, we previously studied the primary photophysical properties of dyes in seven solvents with increased solvent polarity. Their photophysical properties were studied in detail in a previous paper [37]. Here, we shortly discuss the absorption and emission process of PQC and PQPT in three different solvents with the increase in solvent polarities are shown in Figure 4 and tabulated the calculated photophysical figures in Table 1. The PQC and PQPT show bathochromic shifts from 402 to $405 \mathrm{~nm}$ and 423 to $425 \mathrm{~nm}$, respectively, from toluene to methanol. The bathochromic shift in maximum absorption wavelength specifies an increase in intramolecular charge transfer from non-polar to polar solvent. Also, it displays a bathochromic shift in emission spectra such as 487-517 nm for PQC and 545-605 nm for PQPT from non-polar (toluene) to

polar (methanol) solvent, which shows that the excited state is more stabilized in the polar solvents as compared to non-polar solvent. The calculated full width at half maximum (FWHM) from absorption peak was $76 \mathrm{~nm}$ for PQCas well as122 nm for PQPTin toluene, which indicates that the existing dye opens up its use in the field of optoelectronics [43]. The obtained values of Stokes shift for PQC (83-109 nm) and PQPT (119 - $177 \mathrm{~nm}$ ) from toluene to methanol. The increase in Stokes shift from non-polar to polar solvent indicates that the emissive state is more stable than the ground state in a molecule.

The quantum yields of dyes were calculated using the help of standard fluorescein $(\mathbb{\nabla}=0.79)$ in $0.1 \mathrm{~mol} / \mathrm{L}$ $\mathrm{NaOH}$ solution [44] using the following eq. (I)

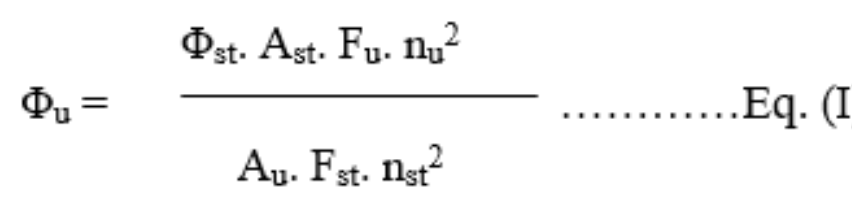

Where $A_{s t}$ and $A_{u}$ are the maximum absorbance value of the standard and unknown sample, $n_{s t}$ and $n_{u}$ are the refractive indices of the standard and unknown and solvent, $F_{s t}$ and $F_{u}$ are the areas of the standard and unknown emission spectra, $\Phi_{\text {st }}$ and $\Phi_{u}$ are the quantum yield of a standard and unknown sample.

In Table 1, the quantum yield in the non-polar (toluene) solution was more relative to the polar (methanol) solution, which signifies the presence of intramolecular charge transfer (ICT) along with twisted intramolecular charge transfer (TICT) in a solvent [45]. The detailed study of the electron transfer process was investigated briefly earlier in the paper [37]. 
The molecular rotation of $\pi$-bridge in PQC and PQPT dye in non-viscous solution causes decreases in the fluorescence intensity. As the viscosity of the solution increased, the fluorescence intensity was increased due to the restriction of $\pi$-bridge rotation. In the previous paper, we have studied the viscosity study of PQC and PQPT dyes in the methanol: PEG 400 system, which proves that the fluorescence intensity of dyes increases as the percentage of PEG 400 increases in methanol due to an increase in viscosity of the solution [37]. The attractive results obtained in the viscosity study of dyes make it interesting to investigate the effect of dye doping in the PMMA, PS, and $\mathrm{PS} / \mathrm{TiO}_{2}$ to open up applications of dyes in the field of polymer.

Table 1: Experimental photophysical data of PQC and PQPT in different solvents

\begin{tabular}{|c|c|c|c|c|c|c|c|c|c|c|}
\hline Comp. & Solvent & $\begin{array}{l}\lambda_{\max }{ }^{a} \\
(\mathrm{~nm})\end{array}$ & $\begin{array}{l}\log \\
\varepsilon^{b}\end{array}$ & $\begin{array}{l}\text { FWHM }^{c} \\
(\mathrm{~nm})\end{array}$ & $\begin{array}{l}\lambda_{\text {onset }^{d}} \\
(\mathrm{~nm})\end{array}$ & $\begin{array}{l}\Delta \mathrm{E}_{\mathrm{opt}}^{e} \\
(\mathrm{eV})\end{array}$ & $\begin{array}{l}\lambda_{\text {exc }}{ }^{f} \\
(n m)\end{array}$ & $\begin{array}{l}\lambda_{\mathrm{em}}{ }^{g} \\
(\mathrm{~nm})\end{array}$ & $\begin{array}{l}\Delta \lambda_{s}{ }^{h} \\
(\mathrm{~nm})\end{array}$ & $\Phi^{i}$ \\
\hline \multirow[t]{3}{*}{ PQC } & Toluene & 402 & 4.95 & 76 & 461 & 2.69 & 404 & 487 & 83 & 0.0782 \\
\hline & DMF & 404 & 4.89 & 79 & 464 & 2.67 & 406 & 506 & 100 & 0.0144 \\
\hline & Methanol & 405 & 4.92 & 78 & 468 & 2.65 & 408 & 517 & 109 & 0.0002 \\
\hline \multirow[t]{3}{*}{ PQPT } & Toluene & 423 & 4.67 & 122 & 491 & 2.53 & 426 & 545 & 119 & 0.0922 \\
\hline & DMF & 423 & 4.65 & 128 & 493 & 2.52 & 425 & 582 & 157 & 0.0208 \\
\hline & Methanol & 425 & 4.56 & 141 & 498 & 2.49 & 428 & 605 & 177 & 0.0002 \\
\hline
\end{tabular}

aabsorption maxima at molar concentration of $\mathrm{c}=\sim 5 \times 10^{-6} \mathrm{~mol} / \mathrm{L}$

${ }^{b}$ molar extinction coefficient calculated from the absorbance at $\mathrm{c}=\sim 5 \times 10^{-6} \mathrm{~mol} / \mathrm{L}$

Cfull width at half maximum (FWHM)

${ }^{d}$ onset absorption edge

$e^{e}$ optical band gap calculated from the equation, $\Delta \mathrm{E}_{\mathrm{opt}}=1240 / \lambda_{\text {onset }}$

fexcitation maxima

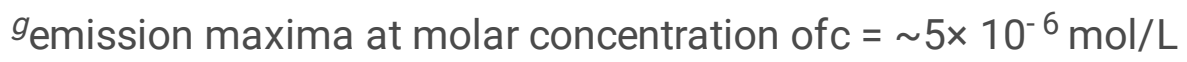

${ }^{h}$ Stokes shift

ifluorescencequantum yield calculated using fluorescein as a standard $(\mathbb{Z}=0.79 \mathrm{in} 0.1 \mathrm{~mol} / \mathrm{L} \mathrm{NaOH}$.

We studied the photophysical properties of PQC and PQPT doped in PMMA and Polystyrene polymer to get primary properties information of dyes in these polymers. We discussed above the brief preparation 
procedure of PQC and PQPT doped polymer in the PMMA, PS, and $\mathrm{PS} / \mathrm{TiO}_{2}$.

The optical emission spectra of PQC and PQPT fluorescent dye in PMMA from 0.01 - 1 wt. \% concentration was shown in Figures $5 \& \mathbf{6}$ and tabulated the obtained data in Table 2. The one major band appears related to singlet electronic transfer from $S_{0} \rightarrow S_{1}$ state within the dye [46]. From, the BeerLambert law concluded that 0.3 wt. \% is the optimum dye concentration for PQC and PQPT with increasing dye concentrations from 0.01 to $1 \mathrm{wt}$. \% in the PMMA polymer. Figure $\mathbf{5}$ shows emission spectra of PQC and PQPT fluorescent films, which excited at the wavelength to maximum absorption value of $404 \mathrm{~nm}$ for PQC and $423 \mathrm{~nm}$ for PQPT. The obtained fluorescence intensity indicates that the dye concentration doped in the polymer is significantly effective in increasing fluorescence intensity up to the dye concentration of $0.3 \mathrm{wt}$. \% for PQC and PQPT dyes. The fluorescence intensity decreases at a maximum dye concentration greater than $0.3 \mathrm{wt}$. \% of dye-doped in polymer with spectra broadening. Figure 6 shows the graph of PQC and PQPT, with a positive slope from dye concentration 0.01 to 0.3 wt. $\%$ and negative slope from 0.3 to $1 \mathrm{wt}$ \%. For PQC and PQPT dyes doped in PMMA polymer from 0.01 to 1 wt. \% shows red-shifted in emission spectra from 504 - 549 nm for PQC and 539 - 563 nm for PQPT, and full with half maxima (FWHM) of emission wavelength was reduced from 117 to $77 \mathrm{~nm}$ for PQC, and 123 to $77 \mathrm{~nm}$ for PQPT was observed. The tabulated the results in Table 2. The above observation can be clarified based on $\mathrm{H}$ and $\mathrm{J}$-aggregate formation. The weak fluorescent intensity in $\mathrm{H}$-aggregate form and decreased fluorescence intensity from dye concentration more than $0.3 \mathrm{wt}$. \% in PMMA polymer for both PQC and PQPT dye [47].

The obtained results of PQC and PQPT doped in PMMA polymer show a maximum emission value at 0.3 wt. \%, which is further used to study the PQC and PQPT dyes in polystyrene polymer.

Yang et al. studied the characterization of nano- $\mathrm{TiO}_{2}$ doped polystyrene to improve the polystyrene sheet tensile strength and heat resistance [41]. The study shows that $0.25 \mathrm{wt} . \%$ of $\mathrm{TiO}_{2}$ doped in polystyrene shows promising results. Hence to improve the photo-stability and efficiency of polystyrene polymer was studied by doping $\mathrm{TiO}_{2}$ nanohybrid with doping of $0.25 \mathrm{wt}$. \% of $\mathrm{TiO}_{2}$ in polystyrene. The $0.3 \mathrm{wt}$ \% PQC and PQPT dye doped in polystyrene polymer were prepared with a thickness of $1 \mathrm{~mm}, 2 \mathrm{~mm}$, and $3 \mathrm{~mm}$ having a doping of $\mathrm{TiO}_{2}$ and without $\mathrm{TiO}_{2}$.

Figure 7 shows the fluorescence spectra of the PQC and PQPT fluorescent sheet, which excited at its maximum absorption value of $404 \mathrm{~nm}$ for PQC and $423 \mathrm{~nm}$ for PQPT. The tabulated obtained data is in Table 3. Both PQC and PQPT show a blue shift in fluorescence spectra (514 to $507 \mathrm{~nm}$ for PQC and 541 to $532 \mathrm{~nm}$ for PQPT) with the increase in fluorescence intensity for polymer thickness $1 \mathrm{~mm}$ to $3 \mathrm{~mm}$ in the absence of $\mathrm{TiO}_{2}$ doping. The polystyrene polymer thickness of $1 \mathrm{~mm}$ containing PQC or PQPT dye-doped with $\mathrm{TiO}_{2}$ shows a remarkable increase in fluorescence intensity of 3.31 fold for PQC and 2.76 fold for PQPT as compared to polystyrene polymer containing PQC or PQPT dye-doped without $\mathrm{TiO}_{2}$. As the polymer thickness increases from $1 \mathrm{~mm}$ to $3 \mathrm{~mm}$ for $\mathrm{TiO}_{2}$ doped polymers, not showing a significant increase in fluorescent intensity and emission wavelength was observed for both PQC and PQPT dye. Also, there was no significant increase in full with half maxima (FWHM) of emission wavelength observed 
for PQC and PQPT dye doped in polystyrene with the absence and presence of $\mathrm{TiO}_{2}$. The tabulated the results in Table 3.

Table 2: Experimental photophysical data of PQC and PQPT dye doped in PMMA with an increase in concentration

\begin{tabular}{|c|c|c|c|c|}
\hline \multirow{2}{*}{$\begin{array}{l}\text { Dye doped concentration } \\
\text { (wt. \%) }\end{array}$} & \multicolumn{2}{|c|}{ PQC doped in PMMA } & \multicolumn{2}{|c|}{ PQPT doped in PMMA } \\
\hline & $\begin{array}{l}\lambda_{\mathrm{emi}}{ }^{a} \\
(\mathrm{~nm})\end{array}$ & $\begin{array}{l}\mathrm{FWHM}^{b} \\
(\mathrm{~nm})\end{array}$ & $\begin{array}{l}\lambda_{\mathrm{emi}}{ }^{a} \\
(\mathrm{~nm})\end{array}$ & $\begin{array}{l}\mathrm{FWHM}^{b} \\
(\mathrm{~nm})\end{array}$ \\
\hline 0.01 & 504 & 117 & 539 & 123 \\
\hline 0.05 & 524 & 94 & 551 & 93 \\
\hline 0.10 & 531 & 86 & 553 & 88 \\
\hline 0.30 & 533 & 85 & 556 & 87 \\
\hline 0.50 & 542 & 76 & 559 & 84 \\
\hline 0.75 & 544 & 78 & 562 & 79 \\
\hline 1.00 & 549 & 77 & 563 & 77 \\
\hline
\end{tabular}

${ }^{a}$ emission maxima

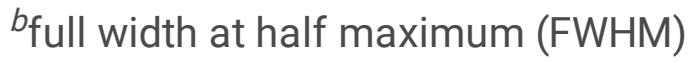

Table 3: Experimental photophysical data of PQC and PQPT in dye-doped in PS with and without $\mathrm{TiO}_{2}$

\begin{tabular}{|c|c|c|c|c|c|c|c|c|}
\hline \multirow{2}{*}{$\begin{array}{l}\text { Sheet } \\
\text { Thickness } \\
(\mathrm{cm})\end{array}$} & \multicolumn{2}{|c|}{$\begin{array}{l}\text { PQC doped in } \\
\text { PS }\end{array}$} & \multicolumn{2}{|c|}{$\begin{array}{l}\mathrm{PQC} \text { doped in } \\
\mathrm{PS} / \mathrm{TiO}_{2}\end{array}$} & \multicolumn{2}{|c|}{$\begin{array}{l}\text { PQPT doped in } \\
\text { PS }\end{array}$} & \multicolumn{2}{|c|}{$\begin{array}{l}\mathrm{PQPT} \text { doped in } \\
\mathrm{PS} / \mathrm{TiO}_{2}\end{array}$} \\
\hline & $\begin{array}{l}\lambda_{\mathrm{em}}{ }^{a} \\
(\mathrm{~nm})\end{array}$ & $\begin{array}{l}\mathrm{FWHM}^{b} \\
(\mathrm{~nm})\end{array}$ & $\begin{array}{l}\lambda_{\mathrm{em}}{ }^{a} \\
(\mathrm{~nm})\end{array}$ & $\begin{array}{l}\mathrm{FWHM}^{b} \\
(\mathrm{~nm})\end{array}$ & $\begin{array}{l}\lambda_{\mathrm{em}}{ }^{a} \\
(\mathrm{~nm})\end{array}$ & $\begin{array}{l}\mathrm{FWHM}^{b} \\
(\mathrm{~nm})\end{array}$ & $\begin{array}{l}\lambda_{\mathrm{em}}{ }^{a} \\
(\mathrm{~nm})\end{array}$ & $\begin{array}{l}\mathrm{FWHM}^{b} \\
(\mathrm{~nm})\end{array}$ \\
\hline 0.1 & 514 & 79 & 539 & 87 & 542 & 101 & 551 & 101 \\
\hline 0.2 & 510 & 82 & 539 & 87 & 534 & 91 & 550 & 102 \\
\hline 0.3 & 508 & 97 & 539 & 87 & 532 & 90 & 550 & 102 \\
\hline
\end{tabular}

${ }^{a}$ emission maxima(c $=0.3$ wt. \% dye doped).

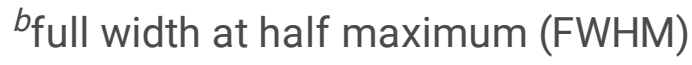

\subsection{Surface Morphology}


The highly soluble pyrrolo-quinaldine based dyes PQC and PQPT in dichloromethane solvent have a 1 wt. $\%$ dye allowing the uniform formation of PMMA thin film by solution casting process was analyzed by scanning electron microscope (SEM). The thin PMMA film of PQC dye shows smooth and without cracks surface. The SEM image of pure PMMA thin film (A), fabricated by solution casting process, shows the same surface morphology as PMMA + $1 \mathrm{wt}$. \% PQC dye thin film (B) with no significant large aggregation formation of dyes molecules in thin-film (B), from which we can conclude that a homogeneous distribution of PQC dye in film formation (Fig. 8). The film surface contains very tiny small crater-like structures with a flat bottom in both the samples, which may form during the solvent evaporation process.

The prepared polystyrene (PS) sheets of $3 \mathrm{~mm}$ thickness have a $0.3 \mathrm{wt}$ \% of PQC dye-doped with $0.25 \mathrm{wt}$. $\%$ of $\mathrm{TiO}_{2}$ or without $\mathrm{TiO}_{2}$ using a melt blending process examined under SEM image. The SEM image of pure PS (A), PS +0.3 wt. \% of PQC dye (B) and PS +0.3 wt. \% of PQC dye +0.25 wt. \% of $\mathrm{TiO}_{2}$ (C) shows a uniform distribution of dye in the polymer. The comparison of polystyrene (PS) polymer with PQC dye doped in without $\mathrm{TiO}_{2}(\mathrm{~B})$ and with $\mathrm{TiO}_{2}(\mathrm{C})$ detected homogenous distribution of $\mathrm{TiO}_{2}$ in polymer and no significant change in the morphology of the infused $\mathrm{TiO}_{2}$ (Fig. 9).

\subsection{Tensile strength and flexural test}

The dye-doped in PMMA, PS and $\mathrm{PS}+\mathrm{TiO}_{2}$ polymers show application in various fields, which may experience different bend and tensile forces during its working. Therefore it is vital to study the physical strength of dye-doped polymers. The Tensile strength of very flexible thin film of pure PMMA and PMMA +1 wt. \% of PQC dye and the flexural test of PS +0.3 wt. \% of PQC dye with 0.25 wt. \% of $\mathrm{TiO}_{2}$ and without $\mathrm{TiO}_{2}$ polymer at three-point bending test was calculated by a computer-operated universal machine. We carried out the tensile strength of the polymer sample with a pure PMMA and PMMA + PQC dye on sample length of $20 \mathrm{~mm}$, a width of $7 \mathrm{~mm}$ and $100 \pm 10 \mu \mathrm{m}$ thickness. In contrast, a flexural test of $\mathrm{PS}+\mathrm{PQC}$ dye with and without $\mathrm{TiO}_{2}$ polymer was carried on sample length of $5 \mathrm{~cm}$, the width of $3.5 \mathrm{~cm}$ and thickness of $3 \mathrm{~mm}$ having applied traverse speed of $10 \mathrm{~mm} / \mathrm{min}$, respectively.

The polymer samples of pure PMMA and PMMA with PQC dye show maximum tensile strength of 2.2 $\mathrm{MPa}$ and 2.0 MPa, respectively, which shows that the addition of PQC dye in PMMA polymer has much less effect on the decrease in tensile strength than the pure PMMA polymer.

The PS + PQC dye with and without $\mathrm{TiO}_{2}$ polymer show a maximum flexural test value of $45.7 \mathrm{~kg}$ and $50.7 \mathrm{~kg}$, respectively, which shows that a $10 \%$ decrease in flexural strength with the addition of $\mathrm{TiO}_{2}$ in $\mathrm{PS}$ as compared to without $\mathrm{TiO}_{2}$ added polymer.

\subsection{Photo-stability}

It is an essential parameter for styryl fluorescent dyes to improve their photo-stability, as they show poor photostability under continued radiation in the presence of oxygen. It is necessary to have a significant photostability of styryl fluorescent dyes when its application is in the field of photonics and optoelectronic devices, and laser. 
The molecular structures and different substitutes of the dyes influence the photostability of styryl dyes. Therefore we used a $500 \mathrm{~W}$ iodine-tungsten (I/W) lamp (working wavelength range $=320-1100 \mathrm{~nm}$ ) for accelerated photostability measurement by continuously exposing the samples. The experimental samples were exposed to irradiation for 36 hours at $28^{\circ} \mathrm{C}$, which corresponds to one year's exposure to the radiation of the terrestrial solar spectrum $[48,49]$. The photostability study of PQC and PQPT was carried out in the same experimental conditions and presented the obtained practical result in Figure 10.

From Fig. 10, it was concluded that the fluorescence intensity at their respective excited maximum absorption wavelength of PQC and PQPT dye sample doped in polystyrene without $\mathrm{TiO}_{2}$ with sample concentration of 0.3 wt. \% of $1 \mathrm{~mm}$ thickness was reduced by $2.85 \%$ and $3.06 \%$, respectively, to its PQC and PQPT dye sample doped in polystyrene with $\mathrm{TiO}_{2}$ having a concentration of $0.3 \mathrm{wt}$. \% and $1 \mathrm{~mm}$ thickness under the monitored conditions. A similar trend was observed with $2 \mathrm{~mm}$ and $3 \mathrm{~mm}$ thickness polymer samples. The photostability study on both the dyes shows that the sample doped with $\mathrm{TiO}_{2}$ was more stable than the sample without $\mathrm{TiO}_{2}$ after 36 hours of irradiation.

Figure 10 shows that PQC has more photostability than PQPT, which may be due to the improved $\mu$ conjugated structure and influence of phenothiazine donor, which reduces the stability of PQPT dye [37]. The above experiment concluded that the addition of $\mathrm{TiO}_{2}$ on the polystyrene polymer with $\mathrm{PQC}$ and PQPT dye improves photo-stability.

\subsection{Thermal stability}

The differential scanning calorimetry (DSC) and thermogravimetric analysis (TGA) were used to study the changes in physical properties of PMMA, polystyrene, and polystyrene doped $\mathrm{TiO}_{2}$ with the addition of 0.3 wt. \% of PQC and PQPT dyes regarding temperature from 30 to $600{ }^{\circ} \mathrm{C}$ in the presence of nitrogen atmosphere to $20^{\circ} \mathrm{C} /$ minute rise in temperature. From figure 11, the thermogravimetric study shows the minimum value of percentage weight loss in dyes under the temperature of $180^{\circ} \mathrm{C}$. The dyes PQC and PQPT display thermal decomposition temperature $(\mathrm{Td})$ at $253^{\circ} \mathrm{C}$ with a $2.0 \%$ reduction in total weight and at $180^{\circ} \mathrm{C}$ with a $3.0 \%$ reduction in total weight. The above experiment concluded that dyes are thermally stable up to $180^{\circ} \mathrm{C}$. The PMMA polymer showed thermal decomposition temperature (Td) at $160{ }^{\circ} \mathrm{C}$ by a $2.2 \%$ reduction in total weight. As the addition of $0.3 \mathrm{wt}$. \% of PQC and PQPT dyes in PMMA polymer showed thermal decomposition temperature $(\mathrm{Td})$ on $179^{\circ} \mathrm{C}$ by $2.0 \%$ reduction in total weight and $177^{\circ} \mathrm{C}$ with a $2.0 \%$ reduction in total weight respectively, which shows that addition of $0.3 \mathrm{wt}$. \% of PQC and PQPT dyes in PMMA polymer does not show more variation in thermal decomposition temperature (Td) of PMMA polymer.

The PS polymer lost $2 \%$ mass upon heating to $334^{\circ} \mathrm{C}$ (Fig.11). Upon addition of $0.3 \mathrm{wt}$ \% of PQC and PQPT dyes in PS polymer, the lost $2 \%$ mass upon heating to $333-338^{\circ} \mathrm{C}$, which shows no significant weight loss due to the addition of 0.3 wt. \% of PQC and PQPT dyes in PS polymer. By adding $\mathrm{TiO}_{2}$ in polystyrene polymer with 0.3 wt. \% of PQC and PQPT dyes shows lost $2 \%$ mass upon heating to $362{ }^{\circ} \mathrm{C}$, 
from which it shows that the addition of $\mathrm{TiO}_{2}$ in PS polymer increases its thermal properties [50]. The tabulated the results in Table 4.

Figure 12 represents the DSC analysis of polymers. The endothermic peak observed for PQC and PQPT at $220^{\circ} \mathrm{C}$ and $180^{\circ} \mathrm{C}$ shows transition temperature for these dyes, respectively [51]. Figure 12 depicts that there was no significant change observed due to the addition of $0.3 \mathrm{wt}$. \% PQC and PQPT dyes in PMMA and PS polymer. The addition of $\mathrm{TiO}_{2}$ in $0.3 \mathrm{wt}$. \% PQC and PQPT dyes in PS polymer show the shift of decomposition temperature from $428^{\circ} \mathrm{C}$ to $439^{\circ} \mathrm{C}$ for $\mathrm{PQC}$ and $434{ }^{\circ} \mathrm{C}$ to $440^{\circ} \mathrm{C}$ for PQPT, which signifies that the addition of $\mathrm{TiO}_{2}$ in $0.3 \mathrm{wt}$. \% PQC and PQPT dyes in PS increase the decomposition temperature.

Table 4: Experimental thermogravimetric data of PQC and PQPT in dye-doped in PMMA, PS with and without $\mathrm{TiO}_{2}$

\begin{tabular}{|c|c|c|c|c|}
\hline \multirow[t]{2}{*}{ Sample } & \multicolumn{2}{|l|}{ PQC } & \multicolumn{2}{|l|}{ PQPT } \\
\hline & $\begin{array}{l}\text { Thermal } \\
\text { decomposition } \\
\text { temperature }\end{array}$ & $\begin{array}{l}\% \\
\text { Weight } \\
\text { loss }\end{array}$ & $\begin{array}{l}\text { Thermal } \\
\text { decomposition } \\
\text { temperature }\end{array}$ & $\begin{array}{l}\% \\
\text { Weight } \\
\text { loss }\end{array}$ \\
\hline Pure Dye & $253^{\circ} \mathrm{C}$ & $2.0 \%$ & $180^{\circ} \mathrm{C}$ & $3.0 \%$ \\
\hline Pure PMMA & $160^{\circ} \mathrm{C}^{*}$ & $2.2 \% *$ & $160^{\circ} \mathrm{C}^{*}$ & $2.2 \% *$ \\
\hline 0.3 wt. \% dye in PMMA & $179^{\circ} \mathrm{C}$ & $2.0 \%$ & $177^{\circ} \mathrm{C}$ & $2.0 \%$ \\
\hline Pure PS & $334^{\circ} \mathrm{C}^{*}$ & $2.0 \% \star$ & $334^{\circ} \mathrm{C}^{*}$ & $2.0 \%$ * \\
\hline 0.3 wt. \% dye in PS & $333^{\circ} \mathrm{C}$ & $2.0 \%$ & $338^{\circ} \mathrm{C}$ & $2.0 \%$ \\
\hline $\begin{array}{l}0.3 \text { wt. } \% \text { dye in } P S+ \\
0.25 \text { wt. } \% \text { of } \mathrm{TiO}_{2}\end{array}$ & $362^{\circ} \mathrm{C}$ & $2.0 \%$ & $362^{\circ} \mathrm{C}$ & $2.0 \%$ \\
\hline
\end{tabular}

$\star_{\text {in the absence of dye }}$

\section{Conclusions}

In this article, novel fluorescent dyes containing pyrroloquinoline acceptor fused with donor carbazole and phenothiazine moiety, PQC and PQPT doped in the polymeric matrix, was prepared to obtain yellow and orange light emission in the poly(methyl methacrylate) and polystyrene films. The dye concentrations were optimized for better optical limiting performance doped in a polymer. The most promising dye concentration ( $0.3 \mathrm{wt}$. \%) for both the dye was concluded on the background of better photophysical properties to obtain the maximum fluorescence intensity and stability of the polymeric matrix. The bathochromic shift was observed as the dye wt. \% in PMMA polymer increased. The dye PQC and PQPT show emission at a wavelength of $528 \mathrm{~nm}$ and $555 \mathrm{~nm}$ respectively in PMMA polymer at the $0.3 \mathrm{wt}$. \% ideal dye concentration in the polymer. The dye PQC and PQPT demonstrate good solubility and compatibility with PMMA and PS polymer. 
The scanning electron microscope shows uniform and homogenous surface morphology of studied polymer samples. As well, the nanohybrid $\mathrm{PS} / \mathrm{TiO}_{2}$ polymer is promising to improve the photo-stability and thermal stability of PQC, and PQPT fluorescent dye was observed with enhancement in fluorescence properties of dyes, but $10 \%$ reduced in the flexural strength of $\mathrm{TiO}_{2}$ doped polymer was observed.

This improves a greener way of synthesizing dyes, optical properties and ease of fabrication process, leading to increasing interest in optical devices, such as organic photonics, optical sensors, lasers, and solar concentrators.

We believe that the existing research work will create more interest in researchers to carry out a more study of these dyes for applications in the field of polymer.

\section{Declarations}

\section{Acknowledgement}

The authors are thankful to UGC-CAS, TEQIP-III for financial support. The instrumental grant from DSTFIST-2018 (Grant section number - SR/FST/ET 582 I/2018/156(C) DATED 24/10/2019). The author's acknowledgement Colourtex Industries Pvt. Ltd. for polystyrene samples preparation.

\section{References}

[1] Curtis M, Watters G. 25 - Cosmetic and Prosthetic Contact Lenses. In: Phillips AJ, Speedwell LBT-CL (Sixth E, editors., London: Elsevier; 2019, p. 463-76. doi:https://doi.org/10.1016/B978-0-7020-71683.00025-8.

[2] Prado AR, Leal-Junior AG, Marques C, Leite S, de Sena GL, Machado LC, et al. Polymethyl methacrylate (PMMA) recycling for the production of optical fiber sensor systems. Opt Express 2017;25:30051-60. doi:10.1364/OE.25.030051.

[3] Kim SJ, Choi B, Kim KS, Bae WJ, Hong SH, Lee JY, et al. The potential role of polymethyl methacrylate as a new packaging material for the implantable medical device in the bladder. Biomed Res Int 2015.

[4] Jiang YG, Fan RW, Peng H, Xia YQ, Chen DY. Tunable solid-state lasers based on PMMA doped with pyrromethene dyes. Laser Phys Lett 2009;6:212-5. doi:10.1002/lapl.200810125.

[5] Hashim A, Abbas B. Recent Review on Poly-methyl methacrylate (PMMA)- Polystyrene (PS) Blend Doped with Nanoparticles For Modern Applications 2019;14:6-12.

[6] Niaounakis M. 3 - Polymers Used in Flexible Packaging. In: Niaounakis MBT-R of FPP, editor. Plast. Des. Libr., William Andrew Publishing; 2020, p. 57-96. doi:https://doi.org/10.1016/B978-0-12-8163351.00003-7. 
[7] Begum SA, Rane AV, Kanny K. Chapter 20 - Applications of compatibilized polymer blends in automobile industry. In: A.R. A, Thomas SBT-C of PB, editors., Elsevier; 2020, p. 563-93. doi:https://doi.org/10.1016/B978-0-12-816006-0.00020-7.

[8] Mujal-Rosas R, Ramis-Juan X. Electrical application of polystyrene (PS) reinforced with old tire rubber (GTR): dielectric, thermal, and mechanical properties. Sci Eng Compos Mater 2013;20:233-44. doi:doi:10.1515/secm-2012-0131.

[9] Song YK, Kim B, Lee TH, Kim SY, Kim JC, Noh SM, et al. Monitoring Fluorescence Colors to Separately Identify Cracks and Healed Cracks in Microcapsule-containing Self-healing Coating. Sensors Actuators B Chem 2018;257:1001-8. doi:https://doi.org/10.1016/j.snb.2017.11.019.

[10] Song YK, Lee T, Kim JC, Lee K, Lee S, Noh S, et al. Dual Monitoring of Cracking and Healing in Selfhealing Coatings using Microcapsules Loaded with Two Fluorescent Dyes. 2019. doi:10.20944/preprints201904.0035.v1.

[11] Bolimowski P, Bond I, Wass D. Robust synthesis of epoxy resin-filled microcapsules for application to self-healing materials. Philos Trans R Soc A Math Phys Eng Sci 2016;374:20150083. doi:10.1098/rsta.2015.0083.

[12] De B, Kumar M, Mandal BB, Karak N. An in situ prepared photo-luminescent transparent biocompatible hyperbranched epoxy/carbon dot nanocomposite. RSC Adv 2015;5:74692-704. doi:10.1039/C5RA12131K.

[13] Dunkers J, Lenahrt J, Van J, Parnas R. Interfacial Response of a Fluorescent Dye Grafted to Glass 2000 .

[14] Yao W, Tebyetekerwa M, Bian X, Li W, Yang S, Zhu M, et al. Materials interaction in aggregationinduced emission (AIE)-based fluorescent resin for smart coatings. J Mater Chem C 2018;6:12849-57. doi:10.1039/C8TC04175J.

[15] McFadden PD, Frederick K, Argüello LA, Zhang Y, Vandiver P, Odegaard N, et al. UV Fluorescent Epoxy Adhesives from Noncovalent and Covalent Incorporation of Coumarin Dyes. ACS Appl Mater Interfaces 2017;9:10061-8. doi:10.1021/acsami.6b13218.

[16] Partanen A, Harju A, Mutanen J, Lajunen H, Pakkanen T, Kuittinen M. Luminescent optical epoxies for solar concentrators. Proc.SPIE, vol. 9175, 2014. doi:10.1117/12.2061721.

[17] Kim J, Oh H, Yoo J, Kim E. Fluorescent Photopolymer for Holographic Patterning. Mol Cryst Liq Cryst 2008;491:67-73. doi:10.1080/15421400802328956.

[18] Kailasnath M, Sreejaya TS, Kumar R, Vallabhan CPG, Nampoori VPN, Radhakrishnan P. Fluorescence characterization and gain studies on a dye-doped graded index polymer optical-fiber preform. Opt Laser Technol 2008;40:687-91. doi:https://doi.org/10.1016/j.optlastec.2007.10.015. 
[19] Kawabe Y, Fukuzawa K, Uemura T, Matsuura K, Yoshikawa T, Nishide J, et al. Formation of photoinduced index grating in azo-carbazole dye-doped polymer. Proc.SPIE, vol. 8474, 2012. doi:10.1117/12.928554.

[20] Ahmed R. Optical Properties of Rhodamine - B Dye Doped in Transparent Polymers for Sensor Application. CHINESE J Phys 2013;51:570. doi:10.6122/CJP.51.570.

[21] Hamdy MS, AlFaify S, Al-Hajry A, Yahia IS. Optical constants, photo-stability and photo-degradation of MB/PMMA thin films for UV sensors. Optik (Stuttg) 2016;127:4959-63. doi:https://doi.org/10.1016/j.ijleo.2016.02.027.

[22] Kleemann M, Suisalu A, Kikas J. Polymer film doped with a solvatochromic dye for humidity measurement. Proc.SPIE, vol. 5946, 2006. doi:10.1117/12.639189.

[23] Mansour AF, El-Shaarawy MG, El-Bashir SM, El-Mansy MK, Hammam M. Optical study of perylene dye doped poly (methyl methacrylate) as fluorescent solar collector. Polym Int 2002;51:393-7. doi:https://doi.org/10.1002/pi.857.

[24] El-Bashir SM, Yahia IS, Al-Harbi F, Elburaih H, Al-Faifi F, Aldosari NA. Improving photo-stability and efficiency of polymeric luminescent solar concentrators by PMMA/MgO nanohybrid coatings. Int J Green Energy 2017;14:270-8. doi:10.1080/15435075.2016.1233422.

[25] Salmani S, Safari E, Majles Ara MH, Zakerhamidi MS. Optical bistability of azo dye-doped PMMA polymer. Opt Mater (Amst) 2013;35:1619-22. doi:https://doi.org/10.1016/j.optmat.2013.04.002.

[26] Deligeorgiev T, Vasilev A, Kaloyanova S, Vaquero JJ. Styryl dyes - synthesis and applications during the last 15 years. Color Technol 2010;126:55-80. doi:10.1111/j.1478-4408.2010.00235.x.

[27] Schwechheimer C, Rönicke F, Schepers U, Wagenknecht H-A. A new structure-activity relationship for cyanine dyes to improve photo-stability and fluorescence properties for live cell imaging. Chem Sci 2018;9:6557-63. doi:10.1039/C8SC01574K.

[28] Yadav UN, Kumbhar HS, Deshpande SS, Sahoo SK, Shankarling GS. Photophysical and thermal properties of novel solid state fluorescent benzoxazole based styryl dyes from a DFT study. RSC Adv 2015;5:42971-7. doi:10.1039/c4ra12908c.

[29] Garcia-Amorós J, Swaminathan S, Zhang Y, Nonell S, Raymo FM. Optical writing and reading with a photoactivatable carbazole. Phys Chem Chem Phys 2015;17:11140-3. doi:10.1039/C5CP01336D.

[30] Damaceanu M-D, Constantin C-P. Tuning the light emission of novel donor-acceptor phenoxazine dye-based materials towards the red spectral range. Opt Mater (Amst) 2018;78:160-71. doi:https://doi.org/10.1016/j.optmat.2018.02.015. 
[31] Miluski P, Kochanowicz M, Zmojda J, Dorosz D. 1,4-Bis(2-methylstyryl)benzene doped PMMA fibre for blue range fluorescent applications. Spectrochim Acta Part A Mol Biomol Spectrosc 2018;192:88-92. doi:https://doi.org/10.1016/j.saa.2017.11.010.

[32] Huo F, Zhang H, Chen Z, Qiu L, Liu J, Bo S, et al. Novel nonlinear optical push-pull fluorene dyes chromophore as promising materials for telecommunications. J Mater Sci Mater Electron 2019;30:12180-5. doi:10.1007/s10854-019-01576-7.

[33] Upadhyay A, Subramanian K. Synthesis and opto-electrical properties of carbazole functionalized quinoline based conjugated oligomer for luminescent devices 2015;28:755-62.

[34] Hsu S-L, Chen C-M, Wei K-H. Carbazole-based conjugated polymers incorporating push/pull organic dyes: Synthesis, characterization, and photovoltaic applications. J Polym Sci Part A Polym Chem 2010;48:5126-34. doi:https://doi.org/10.1002/pola.24311.

[35] Korychenska O, Guzmán D, Serra À, Ramis X, Grazulevicius J V. Fluorescent thiol-epoxy thermosets obtained from diglycidylether of bisphenol A and carbazole based diepoxy monomer. React Funct Polym 2017;116:107-13. doi:https://doi.org/10.1016/j.reactfunctpolym.2017.04.007.

[36] Singh BS, Lobo HR, Krishna Podagatlapalli G, Venugopal Rao S, Shankarling GS. Thiazole based novel functional colorants: Synthesis, characterization and nonlinear optical studies using picosecond Zscan technique. Opt Mater (Amst) 2013;35:962-7. doi:https://doi.org/10.1016/j.optmat.2012.11.018.

[37] Jachak M, Khopkar S, Chaturvedi A, Joglekar A, Shankarling G. Synthesis of novel viscosity sensitive pyrrolo-quinaldine based styryl dyes: Photophysical properties, electrochemical and DFT study. J Photochem Photobiol A Chem 2020;397:112557. doi:https://doi.org/10.1016/j.jphotochem.2020.112557.

[38] Kafafy H, Wu H, Peng M, Hu H, Yan K, El-shishtawy RM, et al. Steric and Solvent Effect in DyeSensitized Solar Cells Utilizing Phenothiazine-Based Dyes 2014;2014.

[39] Sanap AK, Shankarling GS. Environmentally benign synthesis of 4-aminoquinoline-2-ones using recyclable choline hydroxide. New J Chem 2015;39:206-12. doi:10.1039/C4NJ01281J.

[40] El-Bashir SM, Al-Jaghwani AA. Perylene-doped polycarbonate coatings for acrylic active greenhouse luminescent solar concentrator dryers. Results Phys 2020;16:102920. doi:https://doi.org/10.1016/j.rinp.2019.102920.

[41] Sang XM, Yang XJ, Cui ZD, Zhu SL, Sheng J. Preparation and Characterization of Nano-TiO2 Doped Polystyrene Materials by Melt Blending for Inertial Confinement Fusion. J Macromol Sci Part B 2004;43:871-82. doi:10.1081/MB-120030911.

[42] Hamzah M, Mezan S, Tuama A, Jabbar A, Agam M. Study and Characterization of Polystyrene/Titanium Dioxide Nanocomposites (PS/TiO 2 NCs) for Photocatalytic Degradation Application: a Review. 2018. 
[43] Songkhao J, Banerjee R, Debnath S, Narasimhan S, Wannaprom N, Vanalabhpatana P, et al. Structure-property relationship of $\pi$-extended boron-dipyrromethene derivatives towards optoelectronic applications. Dye Pigment 2017;142:558-71. doi:https://doi.org/10.1016/j.dyepig.2017.03.050.

[44] Brouwer AM. Standards for photoluminescence quantum yield measurements in solution (IUPAC Technical Report). Pure Appl Chem 2011;83:2213-28. doi:10.1351/pac-rep-10-09-31.

[45] Khopkar S, Jachak M, Shankarling G. Novel semisquaraines based on 2, 3, 3, 8-tetramethyl-3Hpyrrolo [2, 3- f] quinoline: Synthesis, photophysical properties, AIE, viscosity sensitivity and DFT study. Dye Pigment 2019;161:1-15. doi:10.1016/j.dyepig.2018.09.026.

[46] Cazes, J. (Ed.). (2004). Analytical Instrumentation Handbook (3rd ed.). CRC Press. https://doi.org/10.1201/9780849390395

[47] El-Bashir SM, AlSalhi MS, Al-Faifı F, Alenazi WK. Spectral Properties of PMMA Films Doped by Perylene Dyestuffs for Photoselective Greenhouse Cladding Applications. Polym 2019;11. doi:10.3390/polym11030494.

[48] Masili M, Ventura L. Equivalence between solar irradiance and solar simulators in aging tests of sunglasses. Biomed Eng Online 2016;15:86. doi:10.1186/s12938-016-0209-7.

[49] Bhatia SC. 2 - Solar radiations. In: Bhatia SCBT-ARES, editor., Woodhead Publishing India; 2014, p. 32-67. doi:https://doi.org/10.1016/B978-1-78242-269-3.50002-4.

[50] Leszczyńska A, Njuguna J, Pielichowski K, Banerjee JR. Polymer/montmorillonite nanocomposites with improved thermal properties: Part I. Factors influencing thermal stability and mechanisms of thermal stability improvement. Thermochim Acta 2007;453:75-96. doi:https://doi.org/10.1016/j.tca.2006.11.002.

[51] Demirel B, Yaraş A, ELÇiçEK H. Crystallization Behavior of PET Materials. Balıkesir Üniversitesi Fen Bilim Enstitü Derg 2011;13:26-35.

\section{Figures}




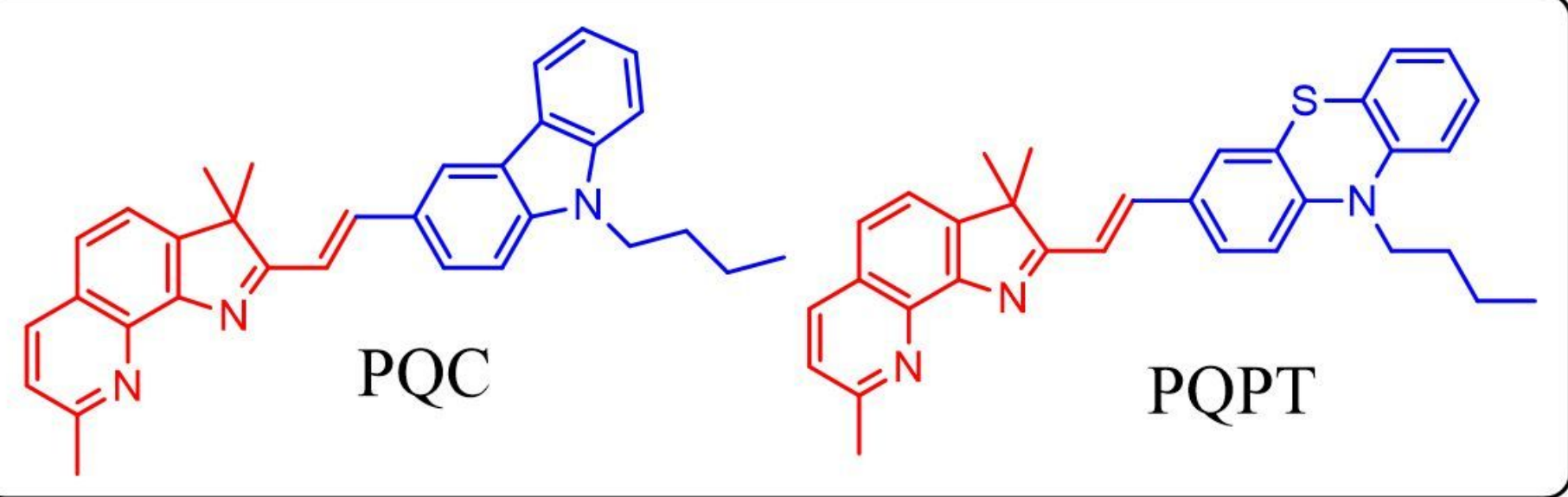

Figure 1

Structures of synthesized styryl dyes

PQC
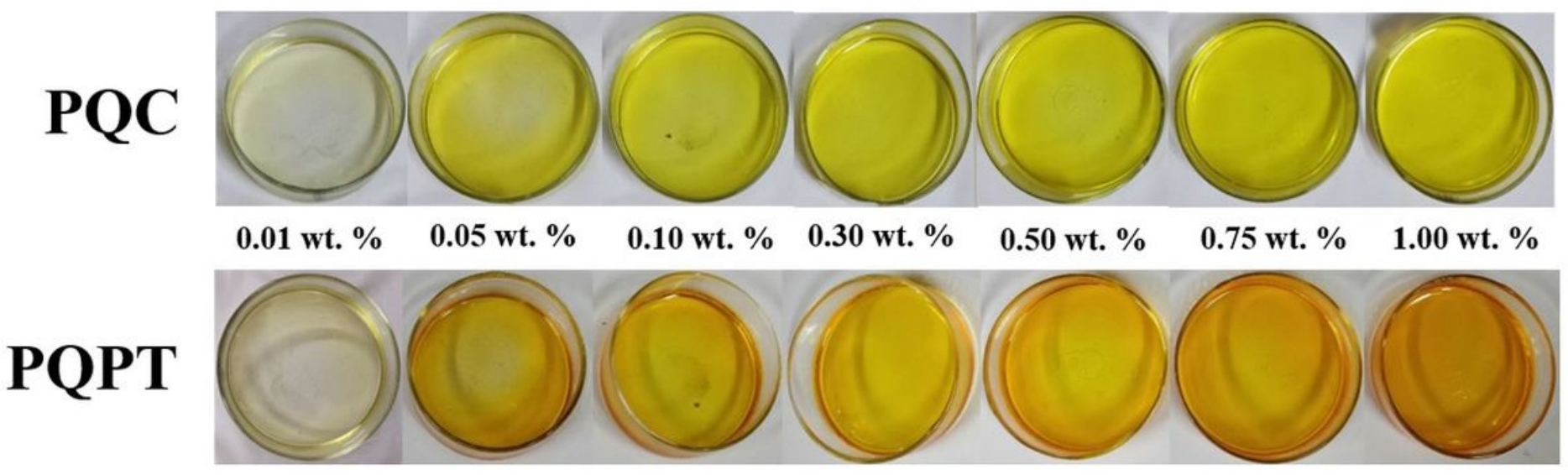

Figure 2

Cast of increasing concentration of PQC and PQPT dyes in PMMA films 
A

\section{Figure 3}

(A) PQC and (C) PQPT dyes doped in polystyrene polymer without TiO2 and (B) PQC and (D) PQPT dyes doped in polystyrene polymer with TiO2 (c = 0.3 wt. \% dye-doped). 

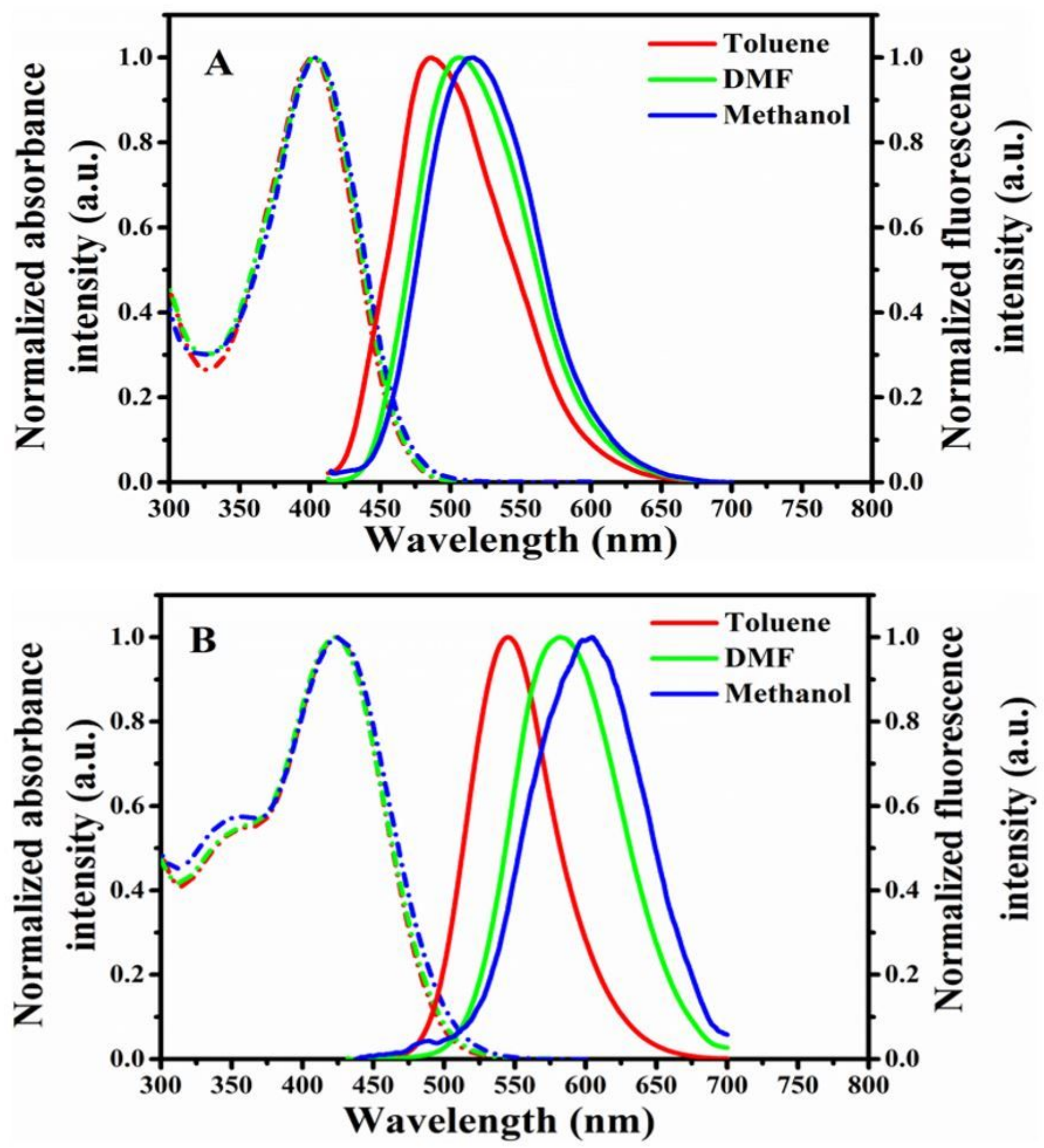

Figure 4

Absorption and emission spectra of PQC (A), and PQPT (B), in various solvents (c $=\sim 5 \times 10-6 \mathrm{~mol} / \mathrm{L})$. 

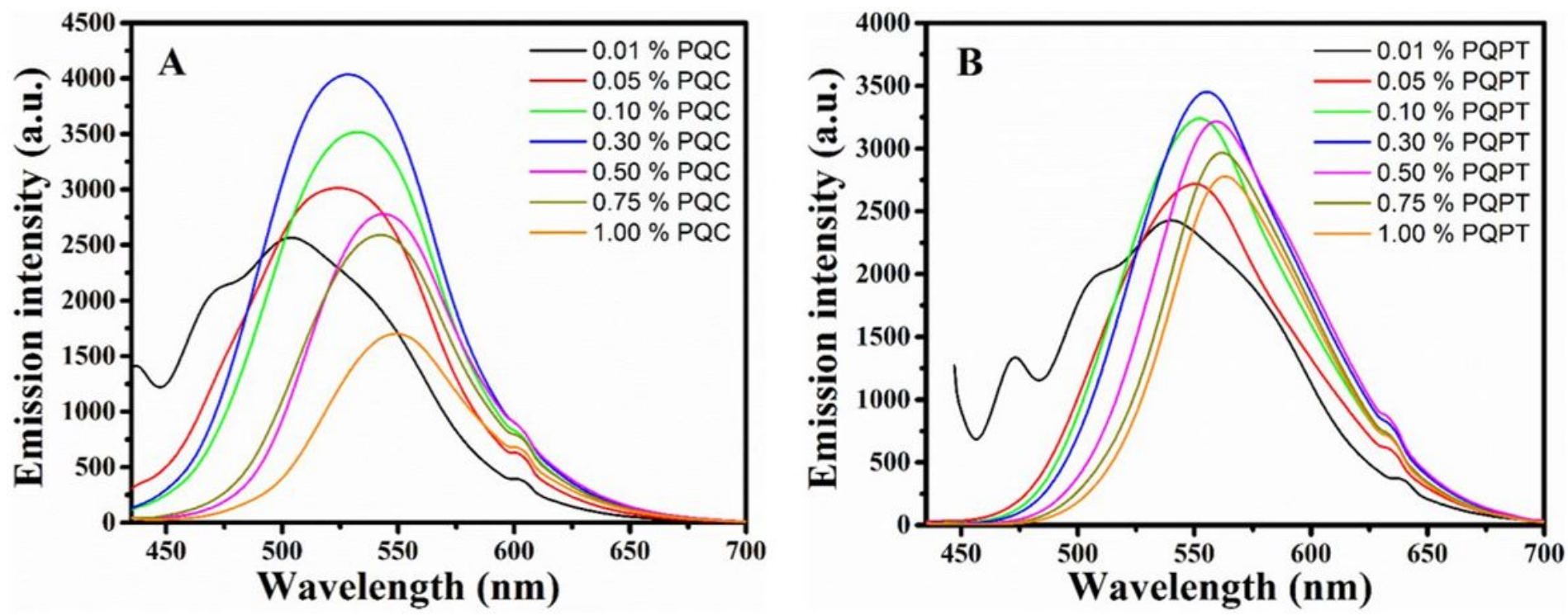

Figure 5

The fluorescence spectra of (A) PQC and (B) PQPT dye doped in PMMA films
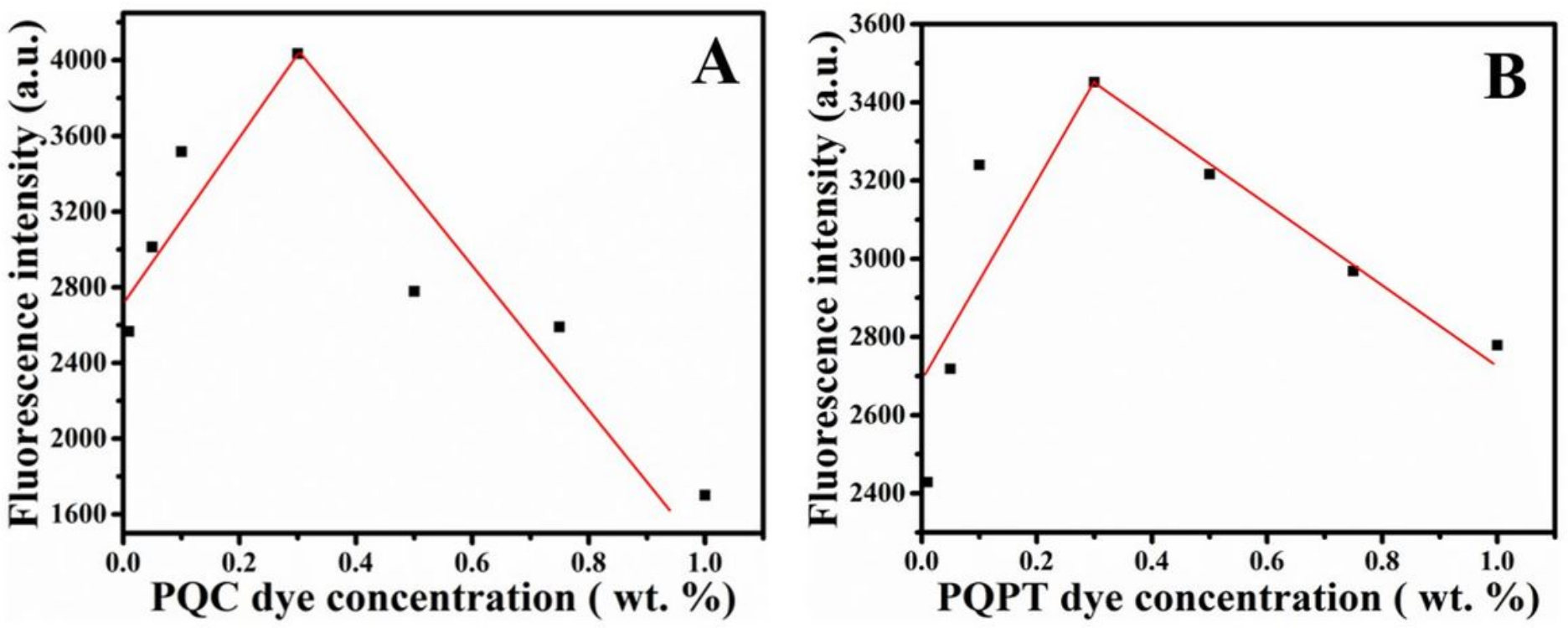

Figure 6

The fluorescence intensity with increasing in the dye concentration (A) PQC and (B) PQPT 

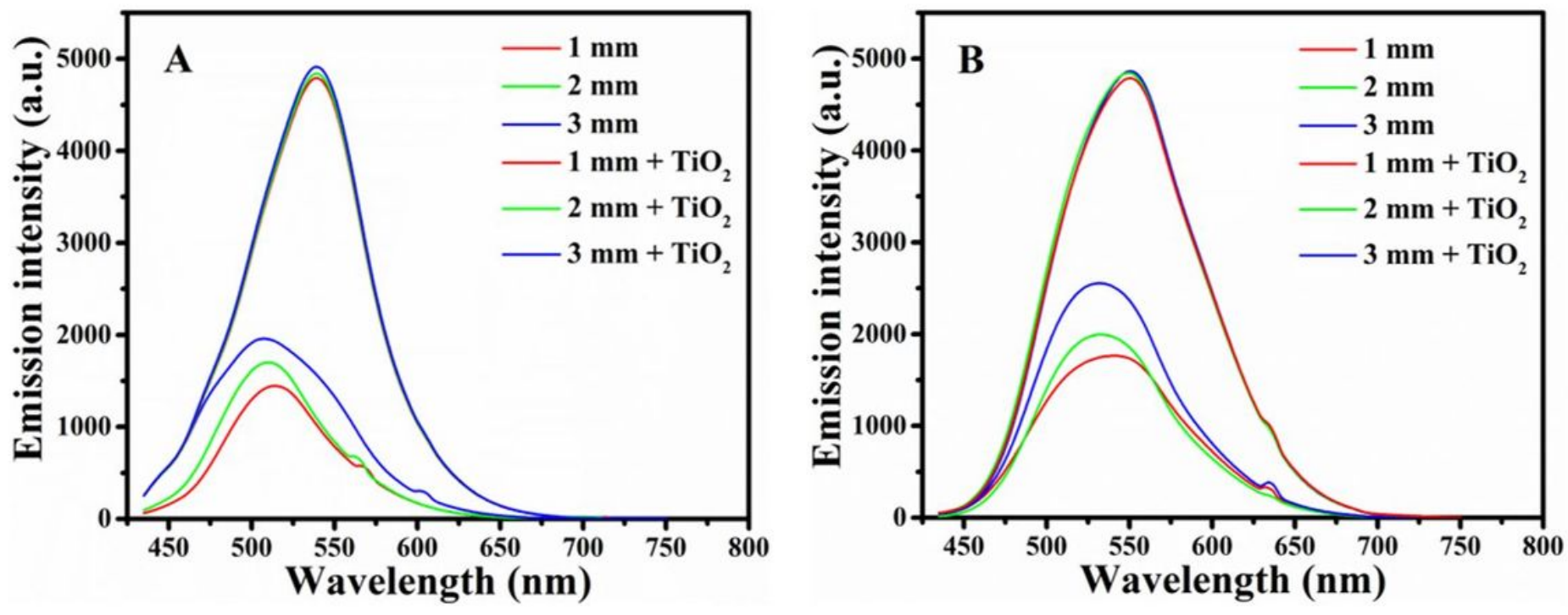

Figure 7

The fluorescence spectra of (A) PQC and (B) PQPT dye doped in polystyrene sheets of thickness $1 \mathrm{~mm}$ to $3 \mathrm{~mm}$ (c = $0.3 \mathrm{wt}$. \% dye-doped).
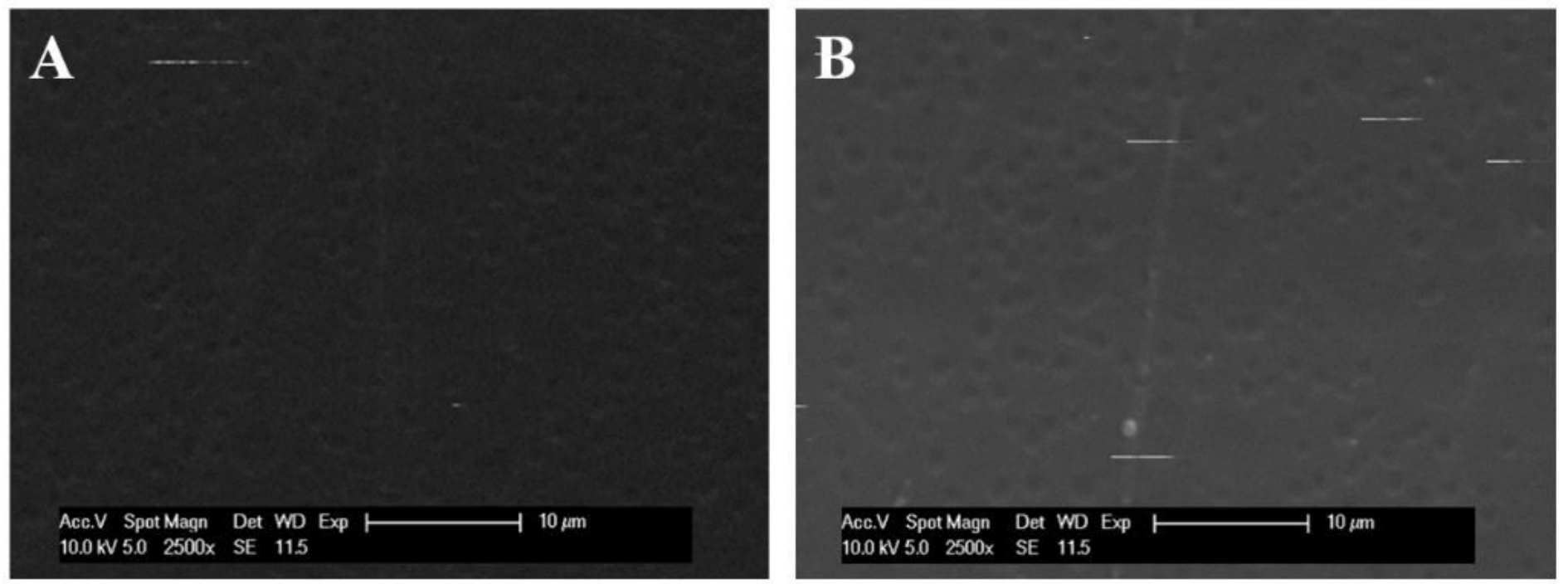

\section{Figure 8}

SEM images of (A) Only PMMA, (B) PMMA + 1 wt. \% PQC Dye 

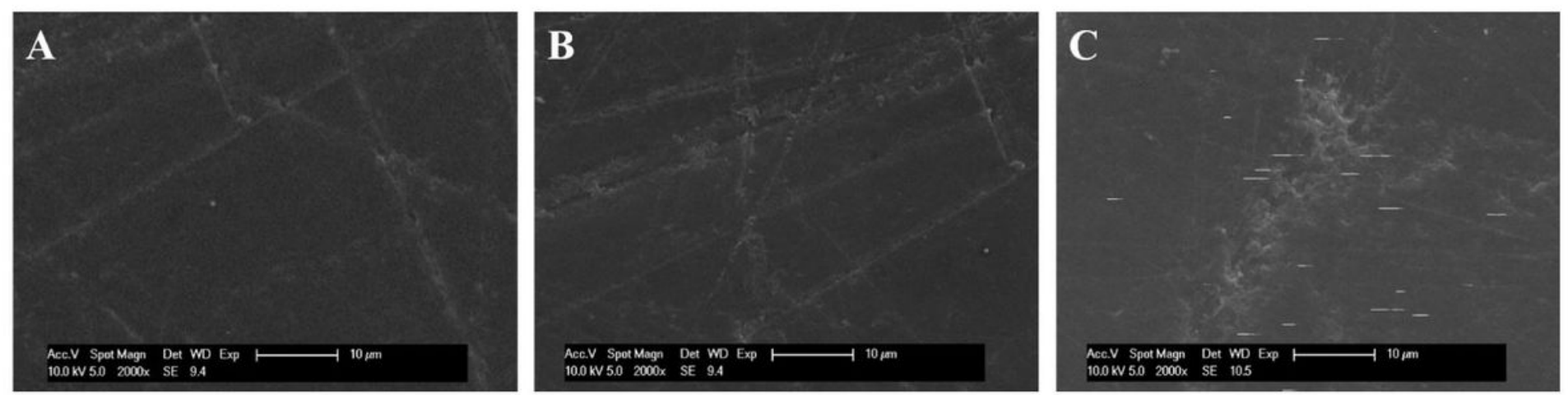

Figure 9

SEM images of (A) Only PS, (B) PS +0.3 wt. \% of PQC dye, and (C) PS +0.3 wt. \% of PQC dye +0.25 wt. \% of $\mathrm{TiO} 2$

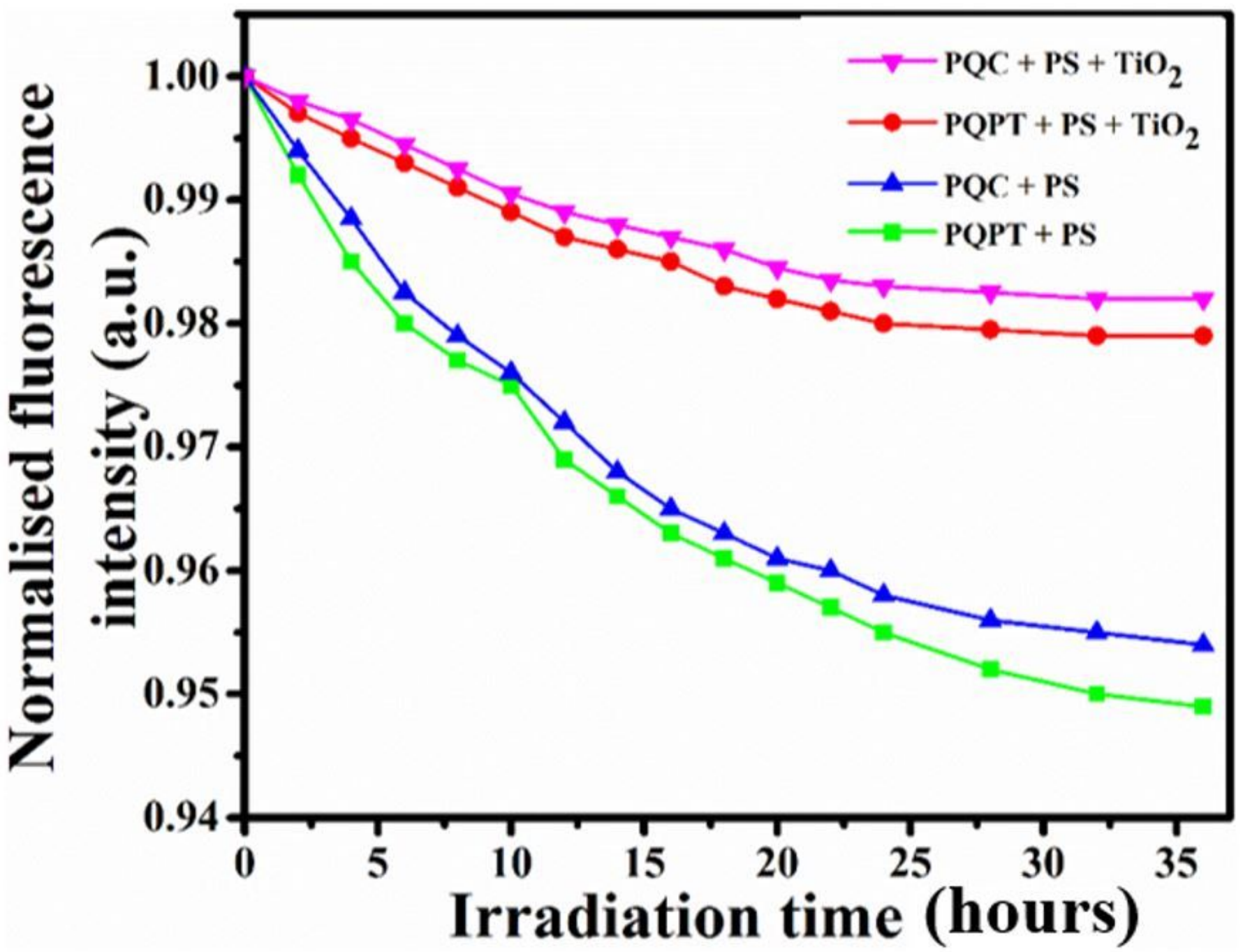

Figure 10 
Accelerated photo-degradation curves of PQC and PQPT dyes doped in PS sheet with and without TiO2
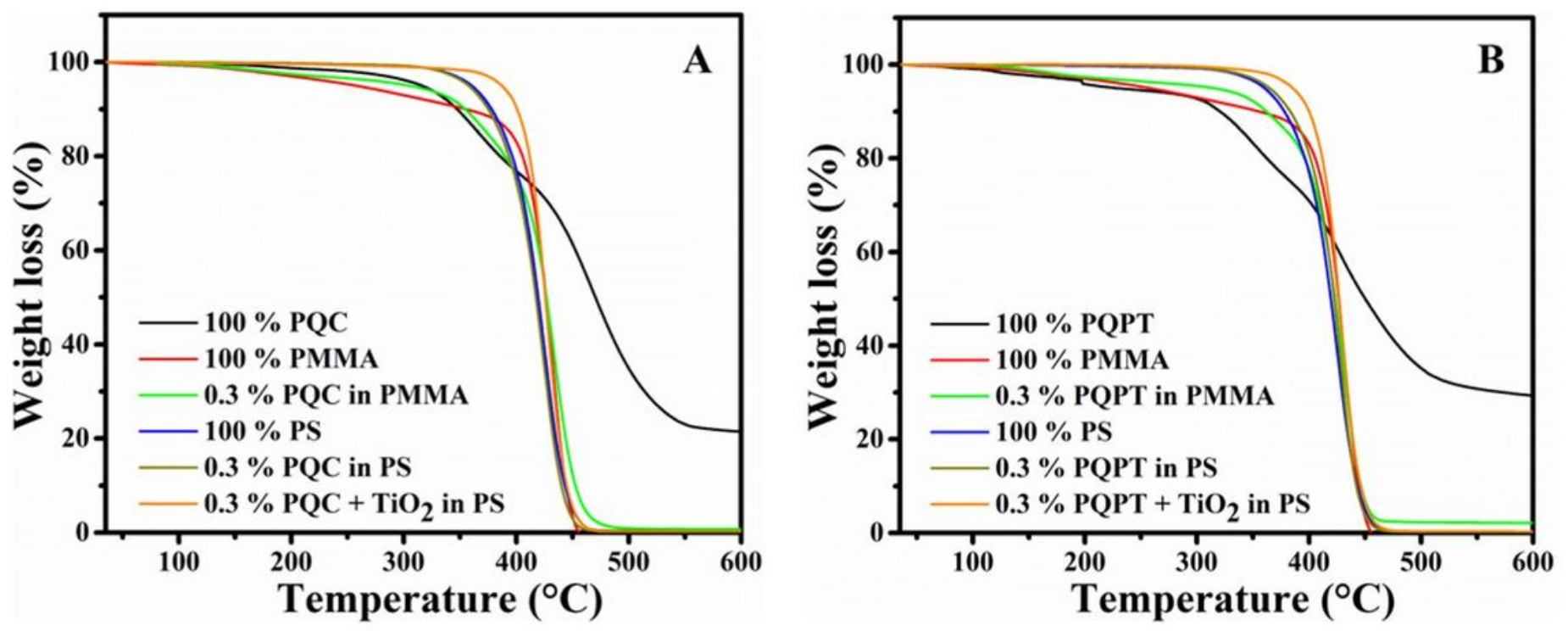

Figure 11

Thermogravimetric analysis (TGA) of (A) PQC and (B) PQPT dye doped in PMMA, PS and PS/TiO2
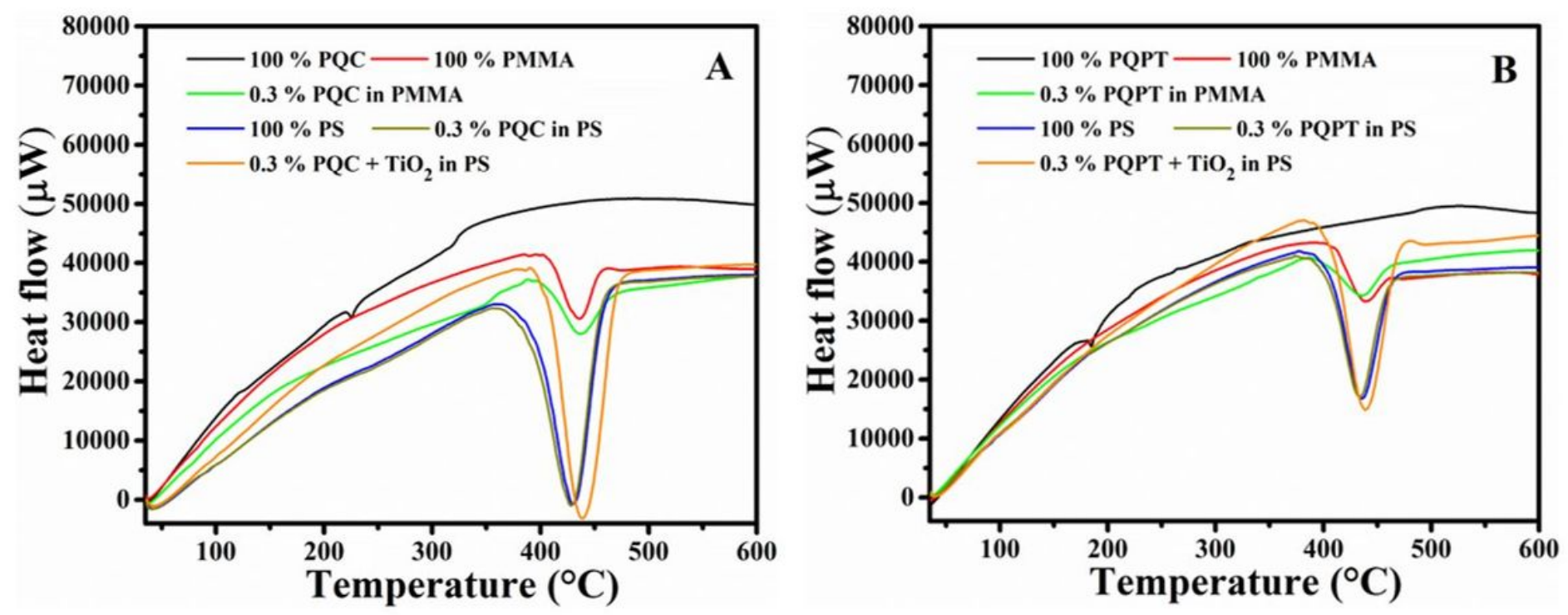

Figure 12

Differential scanning calorimetric analysis (DSC) of (A) PQC and (B) PQPT dye doped in PMMA, PS and $\mathrm{PS} / \mathrm{TiO} 2$ 